O. G. Storozh, G. I. Chuyko, T. S. Kudryk, Ya. V. Mykytyuk, N. S. Sushchyk

\title{
Vladyslav Elijovych Lyantse (in honour of the 100th anniversary of birth)
}

\begin{abstract}
O. G. Storozh, G. I. Chuyko, T. S. Kudryk, Ya. V. Mykytyuk, N. S. Sushchyk. Vladyslav Elijovych Lyantse (in honour of the 100th anniversary of birth, Mat. Stud. 55 (2021), 214-222.

Some pages of biography and main scientific achievements of professor Vladyslav Elijovych Lyantse, a famous mathematician, are presented.
\end{abstract}

The famous Soviet and Ukrainian mathematician Professor Vladyslav Elijovych Lyantse (written also as Władysław Lance or Władysław Lyantse), the founder of modern Lviv school of functional analysis, born 19 November, 1920 in Warszawa, Polska and died 29 March 2007 in Lviv, Ukraine. Starting from the school years his life was connected with Lviv. In the 1930-ies Lyantse's family lived on Kleparivska street. Vladyslav attended Gymnasium No. 9 on Khotynska street and later the natural and mathematical lyceum of Gymnasium No. 12 on Sheptytskykh street. He got interested in mathematics already in school. Vladyslav tried to self-study functional analysis from S. Banach's textbook on differential and integral calculus and praised that textbook as an outstanding example of pedagogical masterpiece.

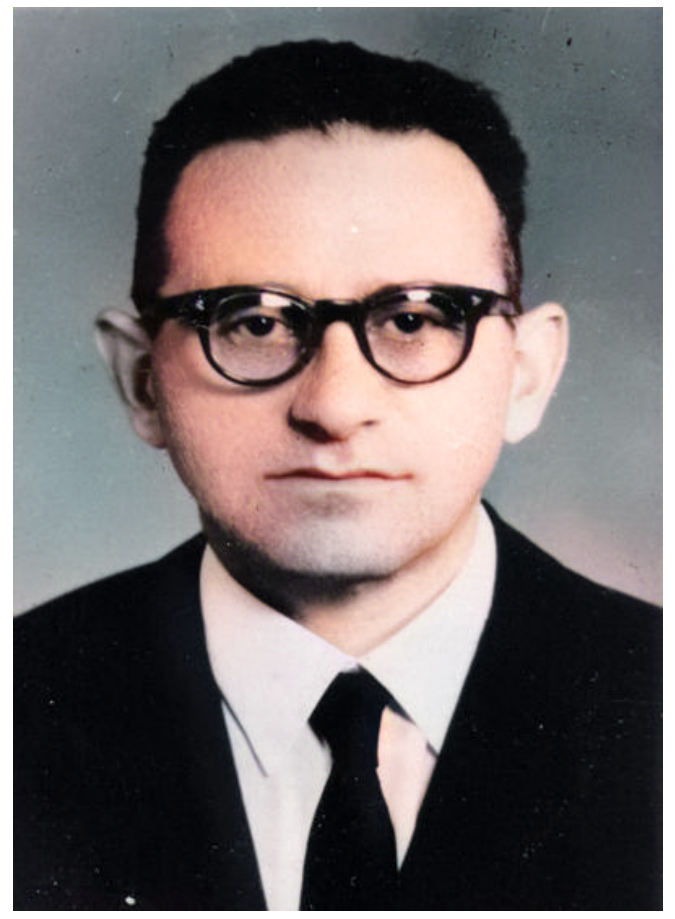

In January 1940, V. Lyantse was enrolled in the Faculty of Physics and Mathematics of Lviv University, which was a world-renowned mathematical center. V. Lyantse attended lectures of Myron Zarytski (a course of mathematical analysis), Władysław Orlicz (a course of algebra), Stanisław Mazur (a course of differential geometry), Juliusz Schauder (a course of theoretical mechanics). At that time, many prominent mathematicians worked at the faculty, in particular, Hugo Steinhaus, Stanisław Saks, Bronisław Knaster. Among coursemates of V. Lyantse there were M. Wiszik (Vishik) and A. Strauss. M. Wiszik, who later became an outstanding mathematician and who was also a friend of Lyantse since gymnasium, kept in mind the brightest memories about their friendship. The icon of Lviv mathematicians was a world-famous scientist, the founder of functional analysis Stefan Banach. V. Lyantse took part in his seminars and later wrote in his memories: "I still can not believe that Banach greeted me by shaking my hand. He treated all mathematician-beginners in that way, and I don't think it was just about western courtesy". That was not actually "western courtesy it was an unconscioustransfer of

2010 Mathematics Subject Classification:01A70.

Keywords: biography; Lyantse.

doi:10.30970/ms.55.2.214-222

(C) O. G. Storozh, G. I. Chuyko, T. S. Kudryk, Ya. V. Mykytyuk, N. S. Sushchyk, 2021 
the leadership from the founder of the Lviv school of functional analysis to the future leader of the Lviv school of functional analysis.

In those remote years, being a second-year student V. Lyantse (together with M. Vishik) obtained his first scientific result: a partial answer to a Problem 192 of Edward Szpilrajn in the legendary "Scottish Book". This partial answer was mentioned in the paper ${ }^{1}$ of SzpilrajnMarczewski published in 1945 in Fundamenta Mathematicae.

War times distracted Vladyslav Lyantse from student bench. At the beginning of the war he was conscripted to a construction battalion, afterwards, he worked in the construction and oil industry in Bashkortostan, and later as a teacher of mathematics.

During 1945-1948, V. Lyantse continued his undergraduate studies at Lviv University. In 1947 Lyantse published his first paper, where he partially confirmed a conjecture of O. S. Kovanko about almost periodic functions.

From 1948 V. E. Lyantse worked at the Lviv Polytechnic Institute and at the same time prepared a candidate's dissertation at the Institute of Mathematics of the Academy of Sciences of the Ukrainian SSR under the supervision of Yaroslav Borysovych Lopatynsky, founder of the Lviv school of differential equations. His researches in the theory of differential equations started with mastering the Cauchy problem for the system

$$
\frac{\partial u_{i}}{\partial t}-\sum_{j=1}^{n} P_{i j}\left(t, \frac{\partial}{\partial x}\right) u_{j}(x, t)=f_{i}(t, x),
$$

where $x=\left(x_{1}, \ldots, x_{n}\right)$ and $P_{i j}$ are polynomials of two variables with coefficients depending on $t$. Necessary and sufficient condition of the well-posedness of the Cauchy problem for such a system in the class of functions with bounded derivatives to a certain order was established by I. H. Petrovskiǔ. V. Lyantse transferred Petrovskiı̌'s results to the class of functions which grow along with their derivatives not faster than $\exp \left(\sum\left|x_{k}\right|\right)^{r}(0<r<1)$, and gave a new integral representation of the solution. However, in the proofs only traditional methods of the theory of differential equations were applied; the specific nature of the operator corresponding to the second term on the left part of (1) was not used. This observation suggested that results of I.H. Petrovskil on the Cauchy problem may be extended to some other types of problems.

Yet new problems often need fundamentally new methods of research. In particular, this assertion is confirmed by the works of V. E. Lyantse on the Cauchy problem for differential equations with operator coefficients in Hilbert space and homogeneous boundary problem for certain classes of parabolic systems of linear differential equations. The theory of linear operators in Hilbert space is widely used in Lyantse's papers. In this respect we have to note that using methods of functional analysis in mathematical physics is nowadays a standard practice, whereas fifty years ago the situation was somewhat different. The above results were included to the Candidate-of-Science dissertation "On the well-posedness of certain boundary value problems of mathematical physics", defended by V. E. Lyantse in April 1951 in Lviv.

In subsequent years, the research interests of Vladyslav Lyantse were directed mainly toward the functional analysis. It seems that such "retraining" in his creative life was not a random phenomenon. Since his first works the scientist had successfully applied methods of the theory of linear operators to problems of mathematical physics. Every time, the natural desire to widen the class of considered problems stimulated the study of a new class of

${ }^{1}$ Edward Szpilrajn-Marczewski, Sur deux propriètès des classes d'ensembles. Fund. Math. 33 (1945), 303307. (French) 
operators. One of such classes (the class of spectral operators) was studied by N. Dunford and his colleagues. Without going into rigorous formulations, we note that spectral operator share many common properties with self-adjoint operators and operators in finite-dimensional spaces.

Questions about the spectrum of an operator tightly correlate with the problem of expansion of an arbitrary element in the domain of the operator in a convergent series of its eigenvectors. The system of such eigenvectors is complete in many interesting applications but in some cases it does not form a basis of unconditional convergence. This fact motivates the problem of creating a more general theory. So, V. Lyantse developed a theory of generalized spectral operators. In the case of discrete spectrum, an operator is spectral in the sense of Lyantse if it has a complete system of eigenvectors, but unlike a spectral operator of Dunford, the angles between the root subspaces corresponding to different eigenvalues need not be bounded below. Let us consider one special application of the theory of generalized spectral operators.

Let $L$ be an operator in $L_{2}(0, \infty)$ defined by the differential expression

$$
L[y]=-y^{\prime \prime}+p(x) y
$$

and the boundary condition $y^{\prime}(0)=\theta \cdot y(0)(\theta \in \mathbb{C})$ and complex-valued potential $p(x)$ of fast decay at infinity. The foundations of the spectral theory of the operator $L$ were elaborated by M. A. Naimark, who showed that this operator may have so-called spectral singularities. Spectral singularities are called "false eigenvalues"as they are spurious solutions of the equation determining the eigenvalues of an operator. These solutions belong to the continuous spectrum but play there a special role. Their existence is accompanied by phenomena, observed neither in the spectral theory of self-adjoint operators nor in the theory of finite-dimensional linear operators.

In the works of Neimark and Levin the expansion in (generalized) eigenfunctions of the operator $L$ was built under the assumption that it does not have spectral singularities. V. E. Lyantse built a similar expansion for operators with spectral singularities. Of course, we can not speak about the complete analogy here. There is a fundamental difference between these two cases because an operator without spectral singularities is spectral, and any function $f \in L_{2}(0, \infty)$ decomposes into an integral by the generalized eigenfunctions of this operator. If the set of all $f$ that can be expanded into such integrals is merely dense in $L_{2}(0, \infty)$ then $L$ is a generalized spectral operator in the sense of Lyantse.

There is no need to write formulas describing the set of such expandable functions $f$. These formulas involve so-called $L$-Fourier transform which turns $L$ into the multiplication by the independent variable (and resembles the classical Fourier transform turning the differentiation into the multiplication by the independent variable) and which in the case of $p(x)=0$ and $\theta=0$ is the standard Fourier cosine transform. V. E. Lyantse proved that every function $f \in L_{2}(0, \infty)$ is determined by its $L$-transform, found the formula of inverse transformation, and established an analogue of Parseval's identity. Lyantse applied his theory of $L$-transformations to one class of boundary problems for partial differential equations. In presence of spectral singularities, it was a success to prove the existence and uniqueness and to find solutions to these problems.

The theory of generalized spectral operators and its application to non-selfadjoint SturmLiouville operators on the semiaxis composed an essential part of Doctor-of-Science dissertation "Some problems of spectral theory of non-selfadjoint operators in Hilbert space successfully defended by V. E. Lyantse in April 1964 in Lomonosov Moscow State University. 
In that year V. E. Lyantse returned back to his Alma Mater, to the Faculty of Mechanics and Mathematics of Lviv University where he worked as a docent and later (1965-1971) as a professor of the chair of geometry (he obtained the title of professor in January 1967). In these years he organized the Lviv seminar on spectral theory of linear operators. Mathematicians from Kyiv, Odesa, Moscow, Leningrad, Baku, Chisinau, Chernivtsi, Drohobych and many other cities presented their results on this seminar. Such famous scientists as B. M. Levi$\tan$ (Moscow), I. T. Gohberg (Chisinau), A. V. Shtrauss (Ulyanovsk), M. L. Horbachuk, V. A. Mykhaylets, V. D. Koshmanenko (Kyiv), S. N. Naboko (St. Petersburg), E. R. Tsekanoskyy (Donetsk) shared their achievements here. Myroslav Horbachuk, a graduate of Lviv University, a corresponding member of National Academy of Sciences of Ukraine mentioned many times that his way in mathematics started due to V. E. Lyantse, the supervisor of his master thesis in Lviv University.

The seminar attracted many gifted students, in particular G. M. Kesselman, V. O. Blashchak, S. H. Shayasyuk, V. M. Kolisnyk, Yu. L. Kyshakevych, I. P. Syroyid, Ye. V. Cheremnykh and others. Exploring the spectral theory of operators, they obtained new interesting results and later defended their PhD dissertations under supervision of V. E. Lyantse.

The seminar leader continued to work actively. He published papers devoted to spectral properties of various classes of differential, difference, and pseudodifferential operators. His works on inverse problems of scattering theory for non-selfadjoint operators and spectral analysis of non-selfadjoint completely regular perturbations of the operator of multiplication by independent variable on the whole axis were highly praised by specialists.

In 1971 Lyantse became the head of the chair of mathematical analysis which in 1973 was unified with the chair of theory of functions and theory of probability, so he became the head of the chair of theory of functions and functional analysis. Simultaneously with intensive pedagogical and organizational activities he was actively engaged in scientific work.

Scientific interests of a true scientist do not fit a Procrustean bed of a single (even very elegant and non-trivial) theory, so at the beginning of 1970-ies V. E. Lyantse together with a group of his students have got interested in the theory of optimal control. Some methods of this theory were applied in the dissertation of a post-graduate student from Egypt Shakhin Mazen.

In the 1970-ies V. E. Lyantse elaborated a theoretical model which appeared to be very useful in the study of some classes of finite perturbations of a closed operator that change not only the law of its action but also its domain. He created a theory (known as the theory of related operators) that could be applied to boundary differential equations both with scalar and operator coefficients. The fundamentals of this theory were developed by V. E. Lyantse jointly with O. H. Storozh who succeeded to establish the solvability conditions for such equations. Later, O. Ya. Mylyo and O. B. Shuvar joined that research and obtained interesting results in their $\mathrm{PhD}$ dissertations. The theory of related operators was also used in the dissertation of M. M. Fedyk who studied operators relevant to a quadratic form, and a post-graduate student from Colombia B. Mayorga who explored Schrödinger operators with singular potential in $\mathbb{R}^{3}$.

Along with that the theory of generalized spectral operators remained to be at the center of interests of Lyantse and his students H. I. Chuyko, Ya. V. Mykytyuk, and a post-graduate student from Syria Mohamed Al-Tundzhi who defended their PhD dissertations on that topic.

However, soon scientific interests of V. E. Lyantse expanded far beyond the spectral theory. His inherent desire to expand his knowledge encouraged him to teach lecture courses 
in topology and mathematical logics (along with the traditional course of functional analysis). Some seminar meetings were dedicated to various problems of modern mathematics, quite distant from functional analysis. Lyantse was interested in tensor reflections and equipped Hilbert spaces, the theory of categories and mathematical foundations of quantum physics. These special seminars generated ideas that were materialized in future scientific achievents of participants of the seminar.

On November 19, 1980, Lviv mathematicians celebrated the 60th anniversary of Professor V. E. Lyantse. Ya. S. Pidstryhach, the leader of Lviv school of mechanics, noticed in his talk at the ceremonial meeting dedicated to this event that Lyantse's special course in the theory of generalized functions was very helpful for solution of many applied problems of mechanics.

A few years later Ya. S. Pidstryhach proposed a deeper cooperation with Vladyslav Elijovych. It was soon discovered that many problems of the theory of elasticity, in which Lviv school of mechanics was engaged, can be reduced to boundary problems, non-classical in the sense that the order of boundary conditions can be higher than the order of equations. V. E. Lyantse showed that in many cases such problems are equivalent to the problem of minimization of some quadratic functional (namely, the energy functional). He established conditions for correct solvability of the considered problems.

In 1980, being already a world famous scientist, V. E. Lyantse with youthful enthusiasm started to study and later to teach researchers and students a new mathematical discipline - nonstandard analysis. Without going into details, let us note that nonstandard analysis allows to consider legally together with the objects of usual (standard) mathematics also some exotic (nonstandard) objects, like infinitely small or infinitely large numbers. Using the transfer principle, one of the basic principles of nonstandard analysis, V. E. Lyantse showed that any linear operator has a complete system of root elements but these elements, in general, are nonstandard. That was the way the pipe dream problem of mathematicians has been resolved.

At first it seemed that for V. E. Lyantse nonstandard analysis was, first of all, a powerful instrument for solving problems of the spectral theory which could not be solved by classical methods. However, he had a different opinion. Anyway the center of his scientific interests during his last twenty years moved steadily towards nonstandard analysis. Among the most important achievements of Lyantse in this area there are:

- formulas of Stock's type for functions of discrete variables;

- the theory of infinitesimal perturbation;

- the theory of nearstandardness on finite sets;

- conversion of a hyperfinite space with a measure into a standard space with a $\sigma$-additive measure.

Professor Lyantse continued to develop intensively nonstandard analysis together with a group of his students, first of all, Taras Kudryk who defended the first "nonstandard" $\mathrm{PhD}$ thesis in Lviv University and Halyna Chuyko who was also involved into the "nonstandard" investigations. The dissertations of Yu. M. Yavorskyi and O. O. Karabyn defended in 2000 in the field of nonstandard analysis were the best gifts by Lyantse's students to the 80th anniversary of their supervisor.

One can get ideas about scientific achievements of Lyantse after reading the list of his published works, the reviews of his papers, the list of $\mathrm{PhD}$ theses of his students (so the badge "for successful achievements in work" was a deserved symbolic award for his contribution). But this is only a piece of his contribution to science. 
It is also worth to mention that V. E. Lyantse translated Moren's monograph "Methods of Hilbert space" (Moscow, Mir, 1965), edited Naimark's book "Linear differential operators" (Moscow, Nauka, 1969) and wrote the appendix to this book.

It is important to emphasize his activity as a member of editorial board of the book series "Modern achievements and their applications" (Kyiv), as one of the leaders (jointly with professor $\mathrm{Yu}$. Y. Cherskyy) of the seminar "Functional analysis and related questions" at the Western scientific center of Academy of Sciences of Ukrainian SSR, and also his participation in many representative forums.

We can not leave unmentioned the fact that during several decades he was the head of editorial board of Visnyk of Lviv University (series of mechanics and mathematics). It is hard to imagine the work of the specialized council for defence of dissertations without his participation. And, finally, along with Lyantse's characteristics as a prominent scientist it would be unpardonable to forget his human qualities of deep respect of human dignity and preservation of his own dignity.

Acknowledgement. The authors are much indebted Dr. Ya. H. Prytula (Lviv) for provided archival documents.

\section{LIST}

\section{OF THE MAIN PUBLICATIONS OF Professor V.E. LyANTSE}

1. T. Kudryk, V. Lyantse, V. Neves, Nonstandard universe based on internal set theory, Functional analysis and its applications, North-Holland Math. Stud., 197 (2004), 155-166.

2. V. Lyantse, G. Chuyko, Rings of projectors and operator-valued measures, Spectral analysis and its applications, Theta Ser. Adv. Math., 2 (2003), 151-160.

3. V. Lyantse, T. Kudryk, About nearstandardness, Functional analysis, (Russian), Ulyanovsk. Gos. Ped. Univ., (2003), no. 38, 63-77.

4. V. Lyantse, T. Kudryk, On near-standardness in Hilbert spaces, Sibirsk. Mat. Zh., 43 (2002), no. 5, 1077-1094.

5. T. Kudryk, V. Lyantse, Standard filling of a product space, Mat. Stud., 16 (2001), no. 2, 169-184.

6. V. Lyantse, Shadow of a measure, Rend. Accad. Naz. Sci. XL Mem. Mat. Appl., 23 (1999), no. 5, $117-123$.

7. V. Lyantse, G. Chuyko, Some nonclassical problem of elasticity theory, Mat. Stud., 11 (1999), no. 2, $177-188$.

8. T. Banakh, V. Lyantse, Ya. Mykytyuk, $\infty$-convex sets and their applications to the proof of certain classical theorems of functional analysis, Mat. Stud., 11 (1999), no. 1, 83-84.

9. V. Lyantse, Yu. Yavorsky, Nonstandard Sturm-Liouville difference operator, II, Mat. Stud., 11 (1999), no. $1,71-82$.

10. V. Lyantse, Yu. Yavorsky, Nonstandard Sturm-Liouville difference operator, Mat. Stud., 10 (1998), no. $1,54-68$.

11. V. Lyantse, Yu. Yavorsky, A nonstandard difference Sturm-Liouville operator, Bull. Polish Acad. Sci. Math., 46 (1998), no. 3, 285-290.

12. V. Lyantse, T. Kudryk, Introduction to nonstandard analysis, Mathematical Studies Monograph Series, 3 (1997), VNTL Publishers, Lviv, 255.

13. T. Kudryk, V. Lyantse, Operator-valued charges on finite sets, Mat. Stud., 7 (1997), no. 2, 145-156, 220.

14. V. Lyantse, Nearstandardness on a finite set, Dissertationes Math. (Rozprawy Mat.), (1997), 369, 63.

15. T. Kudryk, V. Lyantse, G. Chuyko, Nearstandard operators, Mat. Stud., 3 (1994), 29-40, 120.

16. T. Kudryk, V. Lyantse, G. Chuyko, Nearstandardness on finite sets, Mathematical investigations (Ukrainian), Pr. Lviv. Mat. Tov., 2 (1993), 25-34, 107.

17. V. Lyantse, D. Potyagaylo, M. Fedyk, On a boundary value problem of conjugation, Mat. Metody i Fiz.-Mekh. Polya, 30 (1989), 20-24, 101.

18. V. Lyantse, The Stokes formula for functions of a discrete argument, Dokl. Akad. Nauk Ukrain. SSR 6(1991), 16-19, 180. 
19. V. Lyantse, O. Storozh, A nonclassical boundary value problem in the theory of plates, Dokl. Akad. Nauk Ukrain. SSR Ser. A 3 (1990), 15-17, 86.

20. T. Kudryk, V. Lyantse, Near-standardness, Methods for studying differential and integral operators (Russian), "Naukova Dumka", Kyiv, (1989), 116-121, 216.

21. V. Lyantse, On a perturbation that is infinitely small in the strong operator topology, Ukrain. Mat. Zh., 41 (1989), no. 7, 989-992, 1009.

22. V. Lyantse, G. Chuyko, A nonclassical boundary value problem in elasticity theory, Dokl. Akad. Nauk Ukrain. SSR Ser. A 2 (1989), 15-18, 85.

23. V. Lyantse, T. Kudryk, Functions of a discrete variable, Mathematics today '88 (Russian), "Vyshcha Shkola”, Kyiv, (1988), 132-139.

24. V. Lyantse, S. Pidkuyko, A nonclassical boundary value problem, Dokl. Akad. Nauk Ukrain. SSR Ser. A, 12 (1987), 14-16, 85.

25. V. Lyantse, M. Fedyk, Properties of operators generated by sesquilinear forms, Dokl. Akad. Nauk Ukrain. SSR Ser. A 2 (1987), 27-29, 87.

26. V. Lyantse, Nonstandard analysis, Mathematics today '86 (Russian), "Vyshcha Shkola", Kyiv, 1986), 26-44.

27. V. Lyantse, O. Storozh, The resolvent of a perturbed operator, Mat. Metody i Fiz.-Mekh. Polya, 19 (1984), 23-25.

28. V.E. Lyantse, O.G. Storozh, Methods of the theory of unbounded operators, "Naukova Dumka", Kyiv, (1983), 221.

29. V. Lyantse, Is it possible to ignore nonstandard analysis? (Jordan form of an operator in an infinitedimensional space), General theory of boundary value problems, "Naukova Dumka", Kyiv, (1983), $108-112$.

30. V. Lyantse, Kh. Mayorga, On the theory of a one-point boundary value problem for the Laplace operator. II, Teor. Funktsii i Funktsional. Anal. i Prilozhen., (1983), no. 39, 87-94.

31. V. Lyantse, O. Storozh, Conditions for the coincidence of two operators, Visnyk Lviv. Derzh. Univ. Ser. Mekh.-Mat., (1982), no. 20, 14-17, 90.

32. V. Lyantse, O. Storozh, Some perturbation of linear operators with variation in their domain of definition, Mat. Metody i Fiz.-Mekh. Polya, (1982), no. 15, 25-30.

33. V. Lyantse, Kh. Mayorga, On the theory of a one-point boundary value problem for the Laplace operator. I, Teor. Funktsii i Funktsional. Anal. i Prilozhen.,(1982), no. 38, 84-91, 128-129.

34. V. Lyantse, O. Storozh, Operators that satisfy smoothness conditions, Ukrain. Mat. Zh., 34 (1982), no. $4,451-455,539$.

35. V. Lyantse, O. Storozh Operators related to a selfadjoint operator, Visnyk Lviv. Derzh. Univ. Ser. Mekh.Mat., (1981), no. 18, 42-45.

36. V. Lyantse, O. Storozh, A nonlocal boundary condition, Functional analysis, Ulyanovsk. Gos. Ped. Inst., (1981), no. 16, 59-66.

37. V. Lyantse, G. Chuyko, Operator measures, Dokl. Akad. Nauk Ukrain. SSR Ser. A(7), (1981), 7-9.

38. V. Lyantse, V. Kolesnyk, A condition for the correctness of a symbol of a one-dimensional pseudodifferential operator, Vestnik Lvov. Politekhn. Inst., (1980), no. 141, 52-53, 118.

39. V. Lyantse, Ya. Mykytyuk, The tensor product of linear operators, Mat. Metody i Fiz.-Mekh. Polya, (1980), no. 12, 88-89, 122.

40. V. Lyantse, O. Storozh, Mutual adjointness conditions for certain closed operators in terms of abstract boundary operators, Dokl. Akad. Nauk Ukrain. SSR Ser. A(6), (1980), 29-32, 92.

41. V. Lyantse, O. Storozh, Perturbation of a boundary operator, Visnik Lviv. Derzh. Univ. Ser. Mekh.-Mat., (1979), no. 14, 18-21.

42. V. Blashchak, V. Lyantse, The graph norm for a tensor product of linear operators, Visnyk Lviv. Politehn. Inst., (119 Mat. i Meh.), (1977), 11-13, 182.

43. V. Lyantse, Functionals of step functions, Visnyk Lviv. Politehn. Inst. (119 Mat. i Meh.), (1977), 165$167,201$.

44. V. Lyantse, A first order one-dimensional pseudodifferential operator with constant coefficients, Teor. Funkcii i Funkcional. Anal. i Prilovzen. (Vyp. 28), (1977), 64-84, iii.

45. V. Lyantse, The uniqueness of the generalized solution of the system of equations of gas dynamics, Dokl. Akad. Nauk SSSR, (1974), no. 215, 535-538.

46. V. Lyantse, Expansion in the eigenfunctions of a one-dimensional first order pseudodifferential operator with constant coefficients, Dokl. Akad. Nauk SSSR, (1973), no. 213, 38-41. 
47. V. Lyantse, I. Syroid, The spectrality of the perturbed operator of multiplication by the independent variable, Mat. Zametki, (1973), no. 13, 289-296.

48. Yu. Kyshakevych, V. Lyantse, The radical of a certain normed ring, Visnyk Lviv. Derzh. Univ. Ser. Meh.-Mat., (1972), no. 7, 53-60, 133.

49. V. Lyantse, Closed operators in Hilbert space, Teor. Funkcii i Funkcional. Anal. i Prilozhen., (1972), no. $16,165-186,220$.

50. V. Lyantse, On certain relations between closed operators, Dokl. Akad. Nauk SSSR, (1972), no. 204, 542-545.

51. V. Lyantse, Completely regular perturbation of a continuous spectrum. II, Mat. Sb. (N.S.), 84 (1971), no. $126,141-158$.

52. G. Keselman, V. Lyantse, The expansion in principal functions of a nonselfadjoint differential operator of order $2 n$ with spectral singularities,Differencialnye Uravnenija, (1970), no. 6, 497-512.

53. V. Lyantse, Completely regular perturbation of a continuous spectrum, Mat. Sb. (N.S.), 82 (1970), no. 124, 126-156.

54. V. Lyantse, Eigen-element expansion of a nonselfadjoint difference operator, Ukrain. Mat. Zh., (1969), no. 21, 461-474.

55. V. Lyantse, The perturbation of a continuous spectrum, Dokl. Akad. Nauk SSSR,(1969), no. 187, 514517.

56. V. Lyantse, Spectrum and resolvent of a nonselfadjoint difference operator, Ukrain. Mat. Zh.,(1968), no. 20, 489-503.

57. V. Lyantse, A nonselfadjoint one-dimensional perturbation of the operator of multiplication by the independent variable, Dokl. Akad. Nauk SSSR, (1968), no. 182, 1010-1013.

58. V. Lyantse, A non-selfadjoint difference operator, Dokl. Akad. Nauk SSSR, (1967), no. 173, 1260-1263.

59. V. Lyantse, An analog of the inverse problem of scattering theory for a non-selfadjoint operator, Mat. Sb. (N.S.), 72 (1967), no. 114, 537-557.

60. V. Lyantse, Expansion in principal functions of an operator with spectral singularities, Rev. Roumaine Math. Pures Appl. 11 (1966), 921-950; ibid., 11, 1187-1224.

61. V. Lyantse, The inverse problem for a nonselfadjoint operator, Dokl. Akad. Nauk SSSR, (1966), no. 166, 30-33.

62. V. Lyantse, On a differential operator with spectral singularities. II, Mat. Sb. (N.S.), 65 (1964), no. 107, 47-103.

63. V. Lyantse, On a differential operator with spectral singularities, I. Mat. Sb. (N.S.), 64 (1964), no. 106, 521-561.

64. V. Lyantse, Extension of the Fourier L-transform to locally square integrable functions, Dokl. Akad. Nauk SSSR, (1964), no. 158, 1026-1029.

65. V. Lyantse, A non-selfadjoint differential operator of second order on a semi-axis, Dokl. Akad. Nauk SSSR, (1964), no. 154, 1030-1033.

66. V. Lyantse, Unbounded operators commuting with the resolution of the identity, Ukrain. Mat. Zh., (1963), no. $15,376-384$.

67. V. Lyantse, The solution of certain boundary-value problems by the Fourier method, Dokl. Akad. Nauk SSSR, (1963), no. 152, 816-819.

68. V. Lyantse, Inversion formulas in the class of unbounded functions, arising in a second-order boundaryvalue problem, Dokl. Akad. Nauk SSSR, (1963), no. 150, 987-990.

69. V. Lyantse, The eigenfunction expansion of a non-selfadjoint differential operator with spectral singularities, Dokl. Akad. Nauk SSSR, (1963), no. 149, 256-259.

70. V. Lyantse, A generalization of the concept of spectral measure, Mat. Sb. (N.S.), 61 (1963), no. 103, 80-120.

71. V. Lyantse, A generalization of the concept of spectral operator, Dokl. Akad. Nauk SSSR, (1962), no. $142,278-281$.

72. V. Lyantse, Conditions for closedness of the contraction of a self-adjoint operator, Soviet Math. Dokl., (1960), no. 1, 709-712.

73. V. Lyantse, Certain properties of idempotent operators, Teoret. Prikl. Mat. Vyp., 1, (1958), 16-22.

74. V. Lyantse, Rings of unbounded operators based on a resolution of the identity and their representations, Dokl. Akad. Nauk SSSR, (1958), no. 121, 801-804.

75. V. Lyantse,. The integration of operator-valued functions with respect to a spectral measure, Lvov. Politekhn. Inst. Nauchn. Zap. Ser. Fiz.-Mat. Vyp., 38 (1956), 32-44. 
76. V. Lyantse, On the theory of topological fields, Lvov. Politekhn. Inst. Nauchn. Ser. Fiz.-Mat. Vyp., 38 (1956), 29-31.

77. V. Lyantse, On a boundary problem for parabolic systems of differential equations with a strongly elliptic right-hand side, Mat. Sb. N.S., 35 (1954), no. 77, 357-368.

78. V. Lyantse, On differential equations in unitary space, Dopovidi Akad. Nauk Ukrain. RSR, (1952), $258-262$.

79. V. Lyantse, On Cauchy's problem in a domain of functions of real variables, Ukrain. Mat. Zhurnal, 1 (1949), no. 4, 42-63.

Ivan Franko National University of Lviv

Lviv, Ukraine

storog@ukr.net

yamykytyuk@yahoo.com

kudryk@mail.lviv.ua

n.sushchyk@gmail.com 